Proceedings of the 2011 Winter Simulation Conference

S. Jain, R. R. Creasey, J. Himmelspach, K. P. White, and M. Fu, eds.

\title{
AN EXPERIMENTAL FRAME FOR THE SIMULATION OF FOREST FIRE SPREAD
}

\author{
Bahaa Nader \\ Jean Baptiste Filippi \\ Paul Antoine Bisgambiglia \\ University of Corsica \\ UMR CNRS 6134 \\ Campus Grimaldi, Corte 20250, France
}

\begin{abstract}
Wildfire is a constant risk due to its danger on both human and natural resources so modeling and simulation is an important tool to understand and forecast this phenomenon. A basic element of any simulation model is to define a way to store, compare and exchange observation and model results. Without a clear and standardized data structure, results and observations lack usability, inter-comparability and expressiveness.

In this article we propose a well defined data format and API that can represent observation and model outputs. It provides a convenient way to transform fire data and can export any simulated or observed fire into KML for easy visualization. This specification enables the implementation of an experimental frame that is independent of simulation code.

A database of more than 600 fires has been compiled using the API, enabling large scale reanalysis for any code that can be adapted to the proposed experimental frame.
\end{abstract}

\section{INTRODUCTION}

In the last quarter century, the phenomenon of wildfire has attracted researchers in all scientific domains as it has become a major player of disturbance in the circumboreal forest.

As any research subject, wildfire requires observation data to investigate phenomenon and build models. Nevertheless and unlike other geophysical areas, there is not a standard way to collect and store data. Also, wildfire is an environmental system that often acts over large spatial scales, long time frames and heterogeneous units of study. The difficulty is not only formulating this system, but also conceiving higher-level problems with the interaction between modeling paradigms, models interoperability and model reusability. Finally, storing simulations' results is essential to compare simulated fire with an observation or another simulation; but this can only be done in a reusable way.

General theory of modeling and simulation, introduced by Zeigler (Zeigler, Praehofer, and Kim 2000), is the basis of our modeling and simulation environment. This approach of modeling provides a well defined architecture to specify models of a wide variety of modeling paradigms (Zeigler 1987). The DEVS formalism is a set-theoretic formalism (Zeigler, Praehofer, and Kim 2000) and supports specification of discrete event systems in a hierarchical, modular form (Zeigler 1987). It includes a formal representation capable of mathematical manipulation just as differential equations perform this role in continuous systems.

The concept of the Experimental Frame is also developed in the general theory and standard data interchange structure and format. These are the requirements to actually build an experimental frame.

The goal of this paper is to fill the need for a framework adapted to manipulate wildfire observation and simulation data. Currently, this framework is applied to the DEVS based ForeFire code, which simulates forest fire growth (Balbi, Morandini, Silvani, Filippi, and Rinieri 2009, Filippi, Morandini, Balbi, and Hill 2010). 


\section{Nader, Filippi, and Bisgambiglia}

Data definition for the phenomenon of wildfire as well as currently used formats is available in section two and a presentation of the Experimental Frame for the proposed framework in section three. Section four illustrates a detailed presentation for the proposed framework. Section five presents applications of this proposed framework in our simulation environment of forest fire.

\section{REPRESENTATION OF THE WILDFIRE PHENOMENON}

The phenomenon of wildfire is a natural part of most ecosystems (Flannigan, Amiro, Logan, Stocks, and Wotton 2006). It is the uncontrolled combustion of the vegetation fuels that occur in the countryside or a wilderness area (Miller, Landres, and Alaback 2000). The type of vegetation burned differ from one fire to another; so there are different names for this phenomenon, such as forest fires, hill fire, grass fire and brush fire. Each wildfire has its unique proprieties that describe the fire behavior. Those proprieties are the speed of the spread of a fire from the original source, the total burned surface, the ability of jump gaps (roads and fire breaks) and the intensity of fire. There are others factors influencing fire activity such as weather climate and the combustible material present (Ottmar, Sandberg, Riccardi, and Prichard 2007).

\subsection{Types of Wildfire Data Presentation}

Historically, wildfire incidents have been documented as reports mostly to analyze firefighting successes and failures with no computerized formats available. There are two types of presentation available in those reports: graphical and textual.

The graphical presentation is in map form. For example, wildfire could be presented on a map like a set of symbols or keys. The ignition point of a wildfire can be ' $\mathrm{X}$ ', the first contour can be as a set of 'Squares' and the final contour as a set of 'Circles'. The map legend shows the corresponding data for each key. Actual icons and symbols are usually normalized at the country level.

The textual presentation is in the form of text report. Firefighters write these reports to describe the wildfire that they fight against. A report consists of field observations for wildfire's parameters such as fire spread, fire intensity, shape of fire, location of final fire line with a time of observation.

Most of the available information for observed fires exist in this last form. This way of presenting the data is very flexible but it is not convenient for automatic processing, especially in the context of an experimental frame for simulation software.

\subsection{Data Formats of Use in Wildfire Simulation Software}

Nowadays there is a fundamental need to simulate the wildfire in a more efficient way (Finney 1994b). For this domain of research, spatial data of fire provided to simulator is important. This data are essential for compare and ameliorate simulated models and specific data formats have been developed to fit each of these simulation software.

\subsubsection{Farsite}

FARSITE(Finney 1994a) is a simulator of two-dimensional fire growth model (Service 1998) that automatically computes wildfire growth and behavior for long time periods under heterogeneous conditions of terrain, fuels and weather. It was developed by Mark A. Finney.

It combines spatial information on topography, fuels, weather and wind files (Finney and Ryan 1995). This means FARSITE requires a spatial coincident landscape raster information to run (Keane, Garner, Schmidt, Long, Menakis, and Finney 1998).

Two formats are mandatory to run simulation in FARSITE: The Landscape (.LCP) file contains raster data obtained from a GIS for terrain and fuels. All this raster data must be in ASCII grid format, from either ARC/INFO (or ArcView) or GRASS. ASCII raster files must be used to generate a Landscape (.LCP) file 


\section{Nader, Filippi, and Bisgambiglia}

before running a simulation; Initial Fuel Moistures (.FMS): ASCII text file, required to begin the process of calculating site specific fuel moistures at each timed step of the simulation (Finney and Ryan 1995).

For each specific run, a weather and custom model must be defined. Run-specific files: Custom Fuel Model (.FMD) files, Conversion (.CNV) files, Weather (.WTR) files present weather and Wind (.WND) files: for wind distribution. FARSITE output files, consist of Raster Output Maps (arrival time, fire intensity, etc.) and fire contour polygon files (Finney 1994a).

\subsubsection{Landfire}

LANDFIRE (Rollins, Keane, Zhu, Menakis, Hann, and Shlisky 2003) is known as Landscape Fire and Resource Management Planning Tools. It combines vegetation, fire and fuel distribution.

LANDFIRE produces outputs in the form of geospatial products (spatial layers) that describe potential and existing vegetation type, surface, canopy fuel characteristics, fire behavior, fire regime classes, biophysical, environmental site potential and simulated historical fire regimes conditions. These outputs (fuel and risk maps) are compatible with ArcGrids and ArcMap grids, also they are consistent, standardized across the United States (Rollins, Keane, Zhu, Menakis, Hann, and Shlisky 2003), but are not suited to store fire incidents.

\subsubsection{FlamMap}

FlamMap developed by Finney (Finney 2006). It is a tool to simulate and analyze fire behavior (Finney 2006). It computes potential fire behavior characteristics (spread rate, flame length, fireline intensity, etc.). All mentioned input formats for FARSITE are required for FlameMap. The calculations are performed independently for each cell on the gridded landscape (Finney 2006).

\subsubsection{Asphodel}

ASPHODEL is software of tactical situation (SITAC - Situation TACtiques in French) under development, in laboratory of the University of Savoy, France (Dumond, Garitat, Gosse, Michelis, Simonpieri, and Tran 2009). The SITAC is the French graphical representation of a wildfire incident including the fighting actions. The aim of this project is to manage human and material resources deployed to forest fire fighting. It is capable of drawing a SITAC on different base maps.

\subsubsection{ForeFire}

ForeFire has been developed in our laboratory of University of Corsica, Corsica, France (Balbi, Morandini, Silvani, Filippi, and Rinieri 2009). It is based on the environment of DEVS formalism and simulates the forest fire propagation model. Also, ForeFire requires fuels distribution, weather, wind and elevation of terrain (Filippi and Balbi 2009).

These requirements are in the form of input files that are defined in a XML file (Filippi, Morandini, Balbi, and Hill 2010). This file contains simulation parameters, such as the ignition date of forest fire, simulation duration, the point of ignition, the segment of the forest fire shape and the resolution. As mentioned before, it defines input files. These files are: Fuel Model is an XML file, describes the fuel distribution of the terrain; Shape: it is (.shp) file, describes the shape (form) of the terrain; Elevation: it is (.asc) file, presents the elevation of the forest fire location and Wind files, are (.asc), present the wind distribution.

Again, most of these formats have been developed to fit specific software, with no real effort to provide a standard format to store and manipulate a wildfire incident. Next section presents the proposed Experimental Frame for wildfire simulation, where a standard data format is required to actually implement the framework. 


\section{Nader, Filippi, and Bisgambiglia}

\section{EXPERIMENTAL FRAME FOR THE PROPOSED FRAMEWORK}

An Experimental Frame (EF) is a specification of the conditions under which a system is observed or experimented. It is also the operational formulation of the objectives required in a modeling and simulation project (Zeigler, Praehofer, and Kim 2000).

Simulation using DEVS environment facilitates the development of Experimental Frame, which leads to specifying a set of various scenarios. Also, it leads to generating results that can help in comparing the performance of different models. Any EF consists of a generator, an acceptor and a transducer. The generator generates input segments to the system in a known, desired fashion. The acceptor monitors an experiment to verify the desired conditions are met. The transducer observes and analyzes the system outputs. The generator and transducer elements can only be implemented if data exist which can be interpreted by the simulation software.

The EF for the proposed framework, Figure (1), consists of the generator, the acceptor and the transducer. The generator stimulates the Forest Fire Simulation with known data segments [a Fire State from a NetCDF file (.nc), Landscape, Weather and Simulation Parameters]. The acceptor manages the ForestFire simulation, respecting the Simulation Parameters. Finally, the transducer analyzes the output and stocks the State of Fire in NetCDF (.nc) file, which could be used as an input for the generator.

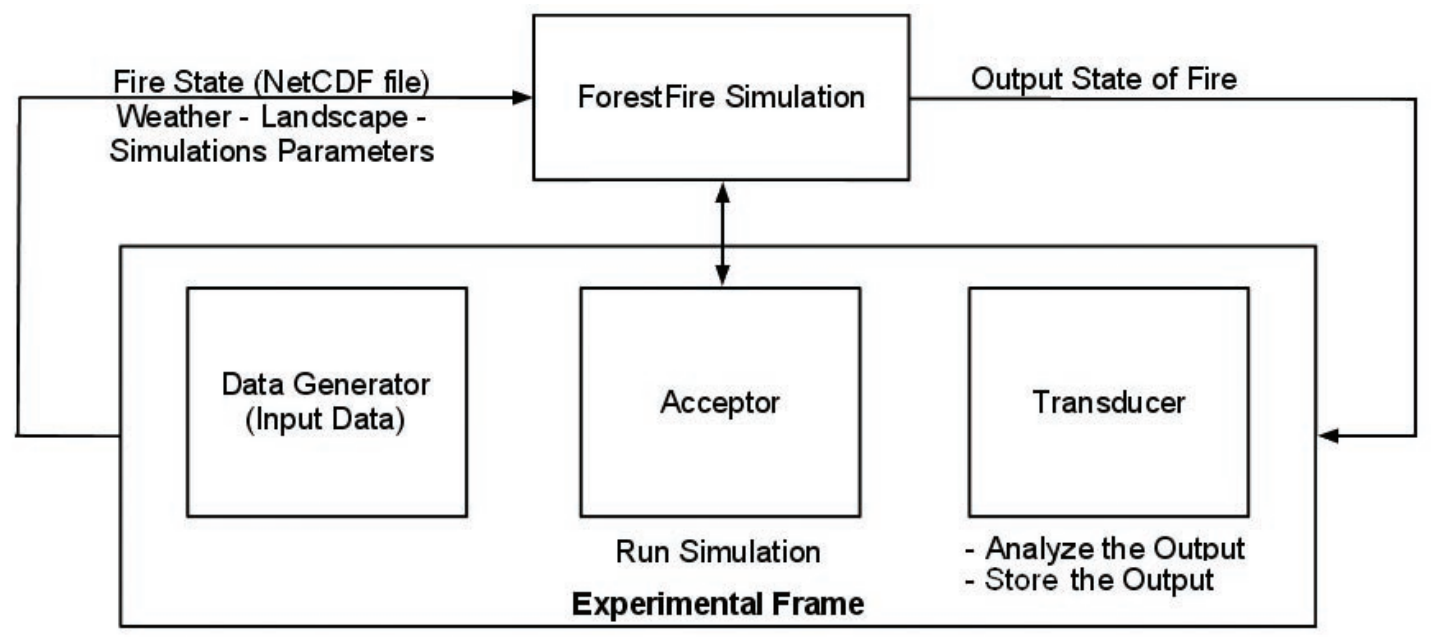

Figure 1: The Experimental Frame for the proposed framework.

The Experimental Frame requires a well defined Input/Output diagram. Figure (2) shows the I/O diagram for the EF for the proposed framework. Input consists of four blocks: 1- Fire State from a NetCDF file (.nc): describes the initial state of fire such as its ignition points, ignition time, area and firefighting action. 2- Landscape defines the distribution of fuels (combustible materials) and the altitude. 3- Weather defines range of wind (speed and direction) and also the weather in this location. 4- Simulation Parameters define the numerical parameters of simulation like duration and resolution of simulation.

These four blocks are considered as the data segments of the data generator.

Output consists of one block: Final Fire State: describes the final state of fire; such as its contours, end time, rate of fire spread. This final state is stored by the transducer in a NetCDF (.nc) file.

As shown in Figure (1), the output file (.nc) can be used as input to the data generator. In this case, contours will be the ignition segment points of the fire and end time will be the ignition time.

Finally, the simulation block represents the periodic aspect, respectingly the Simulation Parameters are managed by the acceptor. 
Nader, Filippi, and Bisgambiglia

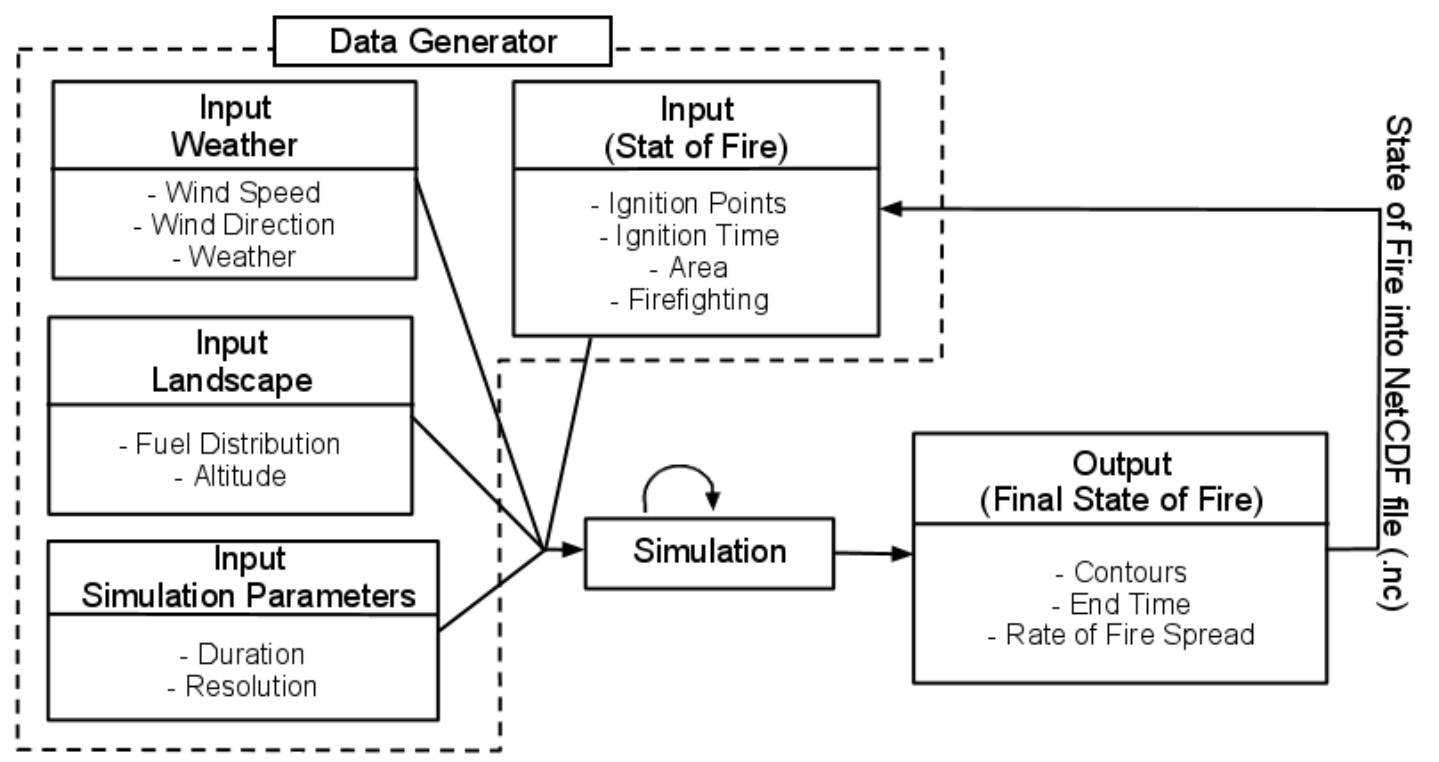

Figure 2: Inputs/Outputs diagram of the Experimental Fram.e

\section{FOREST FIRE EVENT DATA FORMAT}

The development of a data framework has three phases: first the construction of a glossary, second the definition of a file format corresponding to the data on the glossary and third the choice and the configuration of a proper container. This section presents those three phases in details.

\subsection{Construction of a Glossary and Defining the Format}

A glossary is a list of terms for a specific domain of knowledge with the definitions or the explanation for those terms. In our case, we list all data based on observation of forest fire in nature. In other words, we made a domain analysis by consulting information sheets of real cases of wildfire. We studied two real cases: Suartone, Corsica, France occurred in 28/07/2003 at 3:00PM and Favone, Corsica, France in 08/07/2009 at 3:02PM. Table 1 cited all collected data, its format and units.

Although in Table 1 appears sufficient to describe fire behavior, it is not enough to initiate simulation of this fire, because there are other required factors. These factors are the physical proprieties of the place, where the forest fire spreads. Fuel distribution, altitude, weather and wind are needed to simulate a fire. They are the simulation data and are also considered as inputs of the data generator (Figure 2).

Table 1: Glossary of fire incident data collected from information sheets of terrain and the identification of the format.

\begin{tabular}{|l|l|l|l|}
\hline \multicolumn{1}{|c|}{ Data } & \multicolumn{1}{|c|}{ Explanation } & \multicolumn{1}{c|}{ Format } & Unit \\
\hline The Ignition Time Of Fire & Date and time when the fire is triggered & Date - time & - \\
\hline The Final Time Of Fire & Date and time when the fire is extinguished & Date - time & - \\
\hline Ignition Points Of Fire & Points where the fire is triggered & $\begin{array}{l}\text { point (altitude, longitude, el- } \\
\text { evation) or a set of points }\end{array}$ & - \\
\hline Total Burned Surface & It represents the total burned surface & Double & $H a$ \\
\hline $\begin{array}{l}\text { Availability Of Fighting } \\
\text { Tool }\end{array}$ & $\begin{array}{l}\text { It mentions the fighting tool applied on ground } \\
\text { to fight the spreading of a wildfire }\end{array}$ & $\begin{array}{l}\text { A set of data (information: } \\
\text { time of alert, time of arrival, } \\
\text { location, equipment, forces, } \\
\text { quantity of water, .. etc })\end{array}$ & - \\
\hline
\end{tabular}


Nader, Filippi, and Bisgambiglia

\begin{tabular}{|c|c|c|c|}
\hline Fire Passes Known Points & $\begin{array}{l}\text { It describes the fire line passes any knowing } \\
\text { points like a highway, a river, .. etc }\end{array}$ & $\begin{array}{l}\text { A set of data (information: } \\
\text { name, location, damage, .. } \\
\text { etc ) }\end{array}$ & - \\
\hline Rate Of Fire Spread & $\begin{array}{l}\text { It is the horizontal distance that the fire front } \\
\text { moves per unit of time }\end{array}$ & Double & $\mathrm{m} / \mathrm{s}$ \\
\hline Fire Intensity & $\begin{array}{l}\text { It represents the heat released per meter of fire } \\
\text { front }\end{array}$ & Double & $\mathrm{kW} / \mathrm{m}$ \\
\hline Smoke Height & $\begin{array}{l}\text { Is used to estimate the distance between the } \\
\text { edge of flame and the point where the smoke } \\
\text { disappears }\end{array}$ & Double & $m$ \\
\hline Flame Height & $\begin{array}{l}\text { It is used to estimate radiation intensities of } \\
\text { flames }\end{array}$ & Double & $m$ \\
\hline Contours & $\begin{array}{l}\text { A set of points (altitude, longitude, elevation) } \\
\text { that represents the fire shape }\end{array}$ & An array of points & - \\
\hline
\end{tabular}

As a result, wind speed and wind direction can be added to the fire incident data in the glossary (Table 1), because they can be noted with a corresponding observation time. There are two terms added to the glossary: Wind Speed is the horizontal motion of the wind in atmosphere and has a major effect on fire's speed of propagation, its format is double and its unit is $\mathrm{m} / \mathrm{sec}$; Wind Direction, in meteorological reports, is usually given as the direction from which wind is blowing. It defines the direction of fire's propagation, format: double and unit: degree.

Next subsection discuses the container and its configuration with the glossary data.

\subsection{Data Container}

Last phase of framework development can be represented on two steps: the choice of a container that answers our needs and then the configuration of this container. The purpose of this last step is to reinforce a smooth transformation from forest fire simulation to files and vice-versa. We began this phase by the identification of the essential needs. We need a scientific container which provides a standard format as output and machine-independent. We choose NetCDF - Version 4 and HDF - as a container which responds to our needs and realizes our goal. NetCDF - Network Common Data Format - extended from CDF Common Data Format - a library and toolkit that has been developed by NASA. The NetCDF software was developed at the Unidata Program Center in Boulder, Colorado (Rew and Davis 1990). NetCDF consists of a set of libraries and machine-independent data formats that provide the creation, access and sharing of the array-oriented scientific data.

\subsection{NetCDF FRAMEWORK PRESENTATION}

A NetCDF container consists of a set of parameters, which are the dimensions and the variables (Rew and Davis 1990). We configure our NetCDF container with the collected data provided from the glossary. This next section is dedicated for the presentation of our desired framework.

\subsubsection{Dimensions and Variables}

A dimension is used to present either a real physical dimension or to index other quantities. Time, latitude, longitude, or height represent the physical type, in climate simulations. A station or a model-run-number is considered as the other type. Each dimension is defined by a name and a length that is an arbitrary positive integer. A table of dimensions (Table 2) is defined for the desired framework. Naming respects the NetCDF Climate and Forecast (CF) Metadata Convention (Eaton, Gregory, Drach, Taylor, and Hankin 


\section{Nader, Filippi, and Bisgambiglia}

2006). In case a similar dimension is found in CF's table, its same name is used; if not, a proposed name is given.

In order to store a bulk of data in a NetCDF dataset, variables are needed. They are arrays of values of the same type. A variable has a name, a data type and a shape described by its list of dimensions. Also, it has attributes like unit and data range; for the proposed framework, the unit attribute is used to store units of glossary parameters. A set of variables are defined in this designed framework (Table 3). Also, naming respects the NetCDF Climate and Forecast (CF) Metadata Convention (Eaton, Gregory, Drach, Taylor, and Hankin 2006), as dimensions naming.

\section{APPLICATION}

This section is devoted to the python application that implements the data framework. The ontology layer is abstracted in a Python class "ForestFire.py" and tools to create and manipulate instances are available in Python Scripts. Any simulation or observation can be represented by an instance of the ForestFire class. These instances can be stored and loaded as NetCDF files, or created from scratch using the python interface in order to write transcoder to other file formats. As such it represents the "generator" element of the Experimental Frame.

Any instance can also be used to generate outputs, such as Google Earth KML, database record or other evaluation tool, as such it is also the "transducer" element. The next subsection presents the two main tests developed to validate the interface.

\subsection{Representation of Python Script}

A python script is created that contains a class ForestFire. This class consists of all attributes that are data cited in Table 3. This section is devoted to tests that we made to validate our framework in the application phase. Tests have been divided into two types: Test1 is defined as instantiating objects from ForestFire's class from scratch and Test 2 is defined as using the Online Database called Promethee (ARNOULD and CALUGARU 2008) of Forest fires that occurred over the French territory.

\subsection{Test1: Create Forestfire Instance From Scratch}

Test1 presents the creation of an object (from ForestFire Class) from scratch, for which, an analyst must read a report and write the appropriate python script. Five forest fires have been analyzed for this test. We note them by place of event: Saint Cyprien, Corsica, France (09 August 2002 at 09:48AM); Favone, Corsica, France (07 August 2009 at 3:02PM); Sainte-Lucie, Corsica, France (29 August 2006 at 4:50PM); Suartone, Corsica, France (28 July 2003 at 3:00PM) and Opslo, Sardegna, Italy (21 August 2004 at 7:00PM).

Each wildfire's sheet contains two types of data; mandatory data that must be defined during the instantiation (name and date); and supplementary data that can be set after the instantiation (all the other data). After the initialization, object is virtually stored in a NetCDF file that is serialized runtime.

This file contains only defined dimensions and variables, corresponding for available data of the wildfire's sheet. The presentation layer verifies the transformation from ForestFire's object to our NetCDF Framework and vice-versa. Google Earth is used as a presentation tool to verify the result. The process is simple; stored data has been retrieved from file and a new ForestFire instance initialized with this data existed in the file. Finally, a function produces file compatible with Google Earth from all instances that were actually defined in this test (Figures 3 and 4).

\subsection{Test2: Using Data From Promethee}

In Test2, data are fetched from Promethee (ARNOULD and CALUGARU 2008), after objects are created and initialized with data automatically. As mentioned before, Promethee is an online database for forest

fires in the Mediterranean region in France. Developed and launched in 1973 and covers 15 departments 
Nader, Filippi, and Bisgambiglia

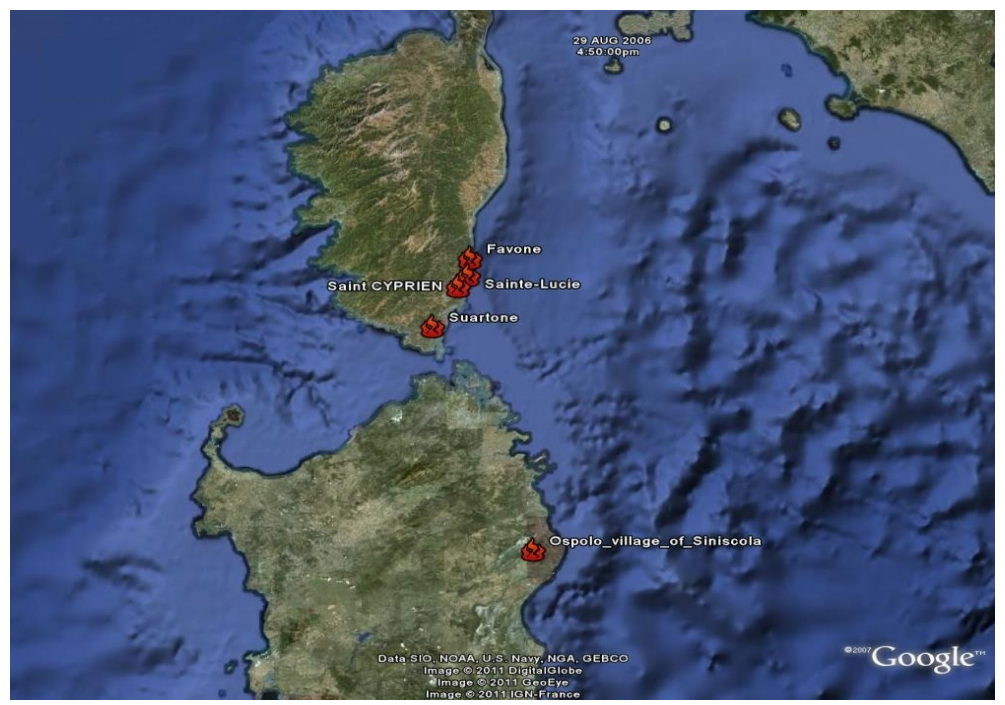

Figure 3: Shows results of Test1. Five forest fires are represented for this test.

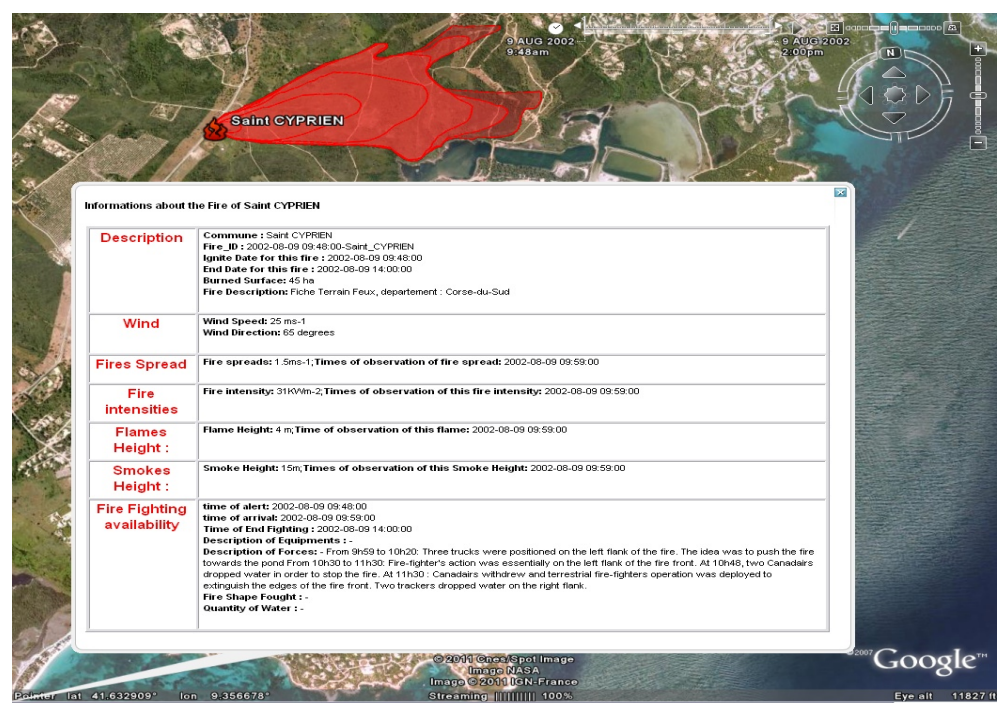

Figure 4: Represents Saint Cyprien's forest fire, which is one of fires showed in Figure 3), with all available data (point of ignition, contours and ignition date of this fire, extended data like wind, fire Spread, ,..etc).

in southeastern of France. Search Criteria are by department, municipality code, time period, contours, total burned surface, ... etc.

The purpose of this test is to retrieve a huge number of forest fires from Promethee. Extract of such is only available in ASCII comma separate values, Fires are created from scratch with a custom reader for this base. ForestFire instances are then serialized in NetCDF, offering the ability to be displayed in KML or used to start simulations. Google Earth has been used to present these results. Figures 5 and 6 show these results of retrieved forest fires (department: North of Corsica, Haute-Corse, period: from 01/01/2003 to 31/12/2003). Number of forest fires stored in the current NetCDF base (files) is 677 fires. Transform operation is done in 10 seconds. 
Nader, Filippi, and Bisgambiglia

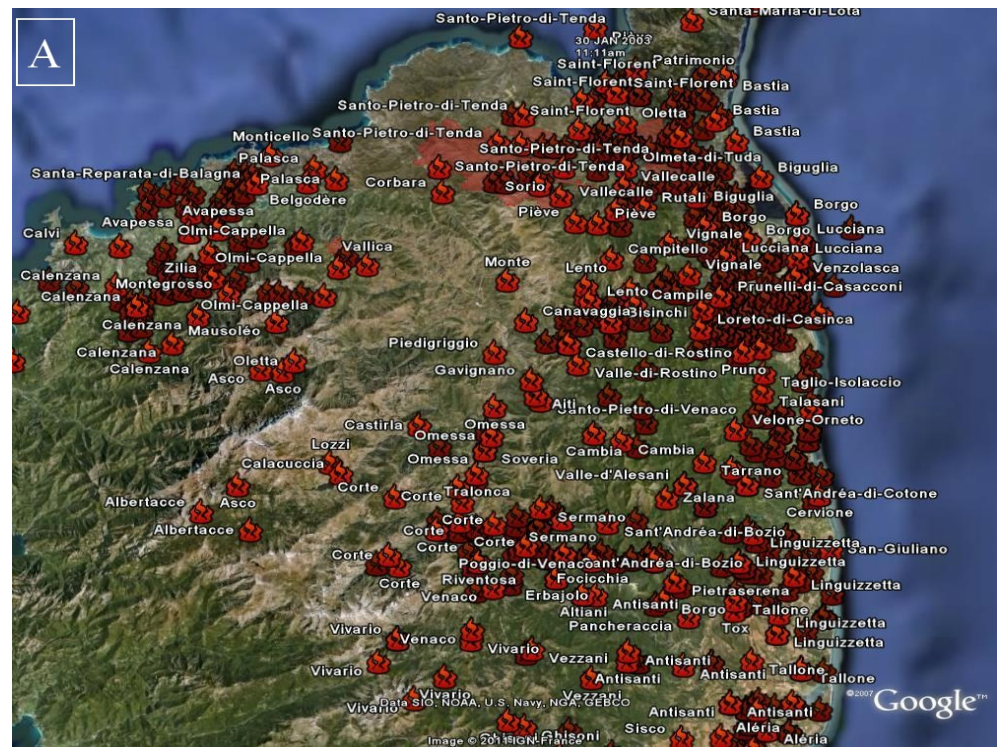

Figure 5: 677 forest fires in North of Corsica, period: from 01/01/2003 to 31/12/2003. (B): Zooming on forest fires and showing extended data of a selected forest fire.

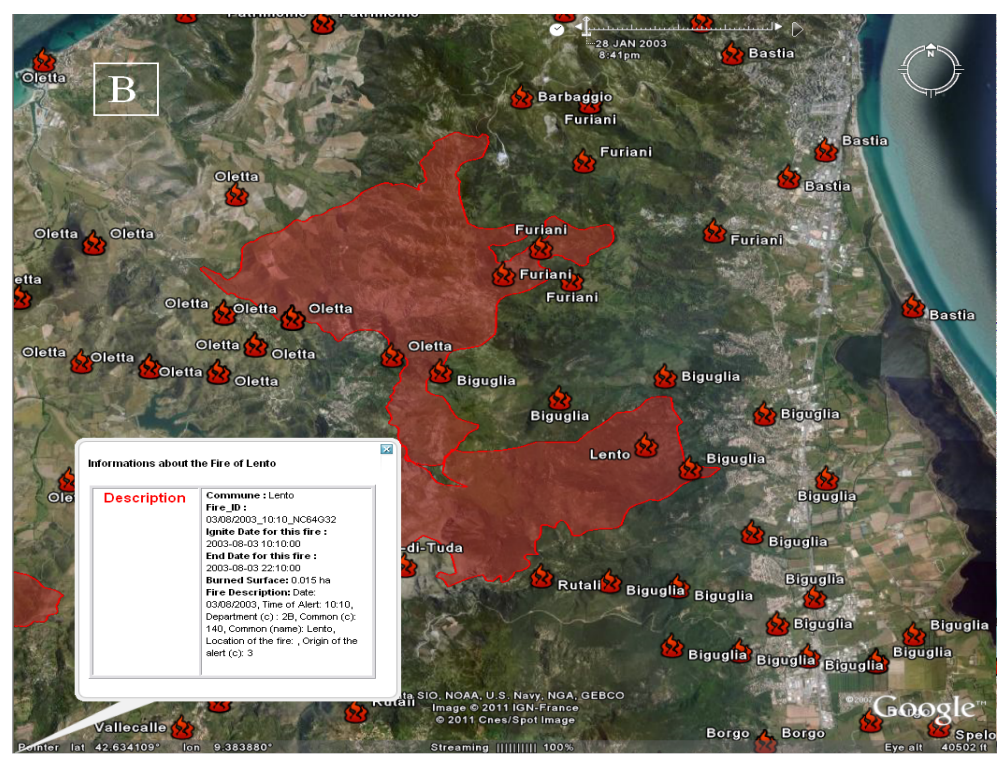

Figure 6: Zooming on forest fires (in A) and showing extended data of a selected forest fire.

\section{CONCLUSION}

This paper has presented the phases of the developed framework, based on NetCDF. The aim of this framework is to transform simulations results of forest fire to NetCDF files (.nc). This transformation leads to comparing forest fires simulations with corresponding observed fires and to replay stored forest fires in future for other purposes. A set of Python script is available upon request to write data reader/writer to this format. 


\section{Nader, Filippi, and Bisgambiglia}

Tests have been applied to verify that this framework can represent the available data. The obtained results show that the developed framework is well suited to store forest fires simulation result. We hope to enrich the database with a maximum of events, in order to provide the test base for the scripts.

Our future work is to integrate simulation software directly in this framework in order to realize large automatic reanalysis of forest fire events, that may help to enhance forest fire models for all compliant software.

\section{ACKNOWLEDGMENTS}

This research is developed within the IDEA project ANR-09-COSI-006-01

\section{A APPENDICES}

Here we present tables of dimensions and variables of the proposed NetCDF framework. Table 2 shows dimensions of the NetCDF framework. Table 3 presents variables defined in the NetCDF framework.

Also, We present some code lines extracted from the python script presented in APPLICATION (section 5).Code lines in Listing 1, shows the creation of an instance of ForestFire from scratch (Test1) and initialization of its attributes with available data exist in the fire report. Listing 2 shows the code used to retrieve fires from NetCDF (.nc) files and generate an appropriate KML file to visualize results of this test.

Code lines in Listing 3, presents functions of Test2. First function is load that loads fetched forest fires data from Promethee files into an array. ForestFiretoNC function transforms an array of forest fires into NetCDF files, as done before in Test1. NewForestFireFromNC returns forest fire from a NetCDF file. Finally genKML generates a KML file to visualize the retrieved forest fires from NetCDF files on Google Earth, used before in Test 1 .

Listing 1: Some lines of the python script are used to initiate an object from ForestFire class and set its attributes and the addition of ForestFire instance to an array

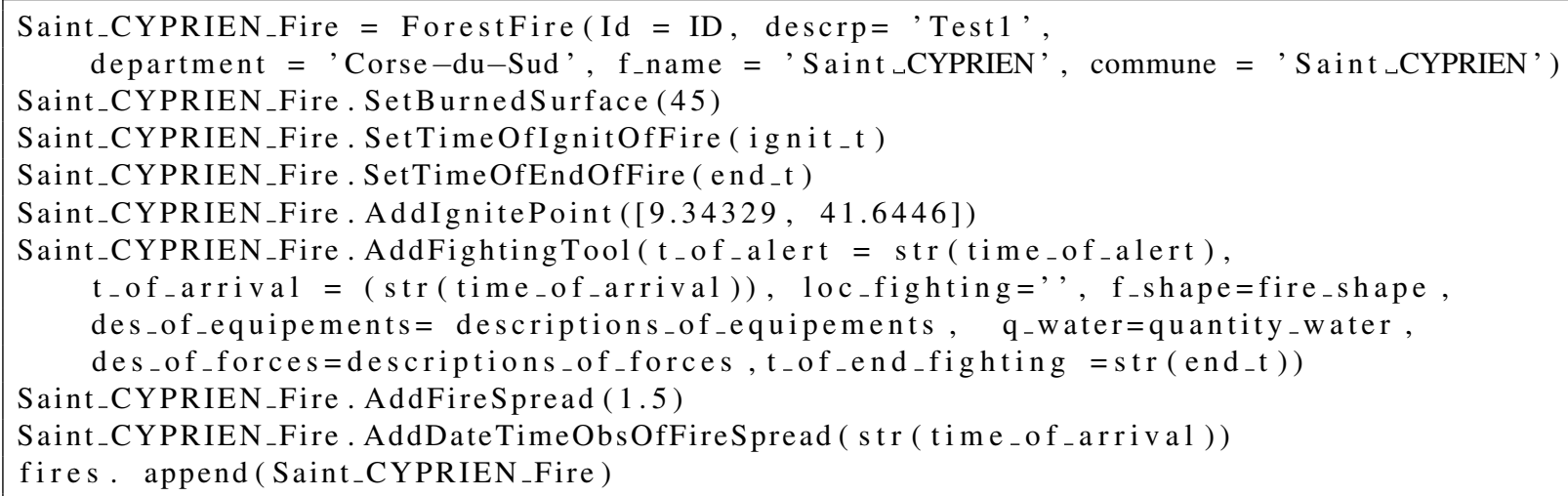

Listing 2: Code presents the transformation the array of all ForestFire instances to NetCDF files; the retrieving form files; and the generation of KML file for retrieved fires

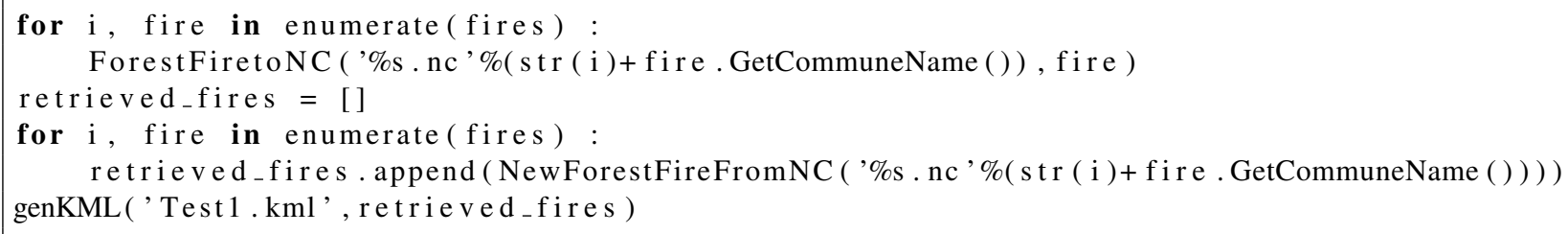




\section{Nader, Filippi, and Bisgambiglia}

Listing 3: Script presents loading fires data from Promethee files; transformation fires to NetCDF; and generating a KML file for the retrieved fires from NetCDF files

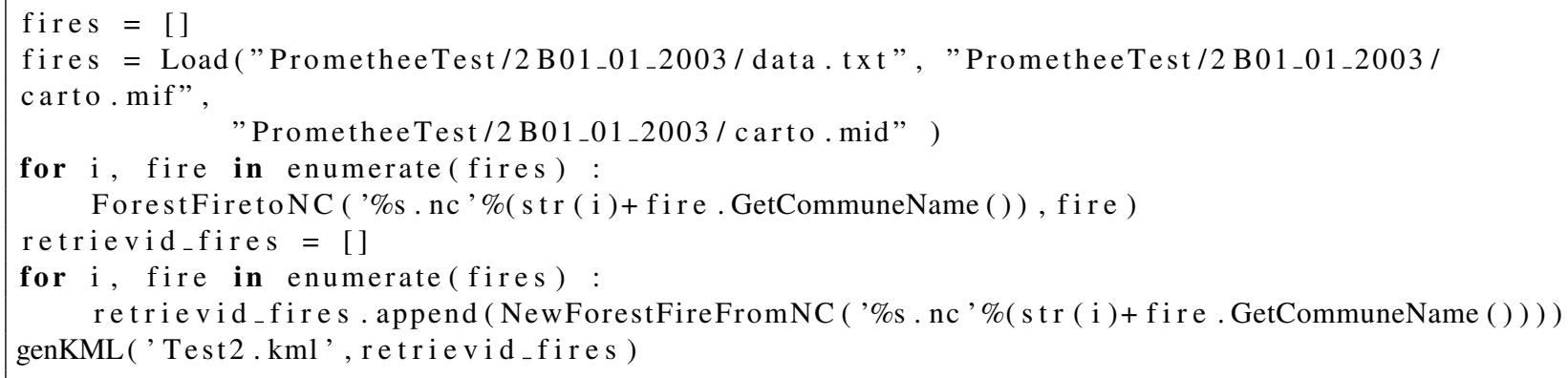

Table 2: Defined Dimensions for the proposed NetCDF framework.

\begin{tabular}{|c|c|c|}
\hline Dimension & Length & Explanation \\
\hline Fire Representation Text & 1 & $\begin{array}{l}\text { It is for any fire information in text form, will be saved in NetCDF } \\
\text { file like ID, Name and Description }\end{array}$ \\
\hline Time & 1 & It is devoted for the time dimension (physical dimension) \\
\hline $\mathrm{X}$ & UNLIMITED & It presents the spatial dimension in $\mathrm{X}$ axis (physical dimension) \\
\hline $\mathrm{Y}$ & UNLIMITED & It presents the spatial dimension in $\mathrm{Y}$ axis (physical dimension) \\
\hline Point 2D & 2 & $\begin{array}{l}\text { it defines the longitude and the latitude at a given point (index } \\
\text { dimension) }\end{array}$ \\
\hline $\begin{array}{l}\text { Number } \text { Of } \text { Ignition } \\
\text { Points }\end{array}$ & UNLIMITED & It handles number of ignition points of a fire front (index dimension) \\
\hline Wind & 1 & $\begin{array}{l}\text { It presents the wind dimension used for wind speed and wind } \\
\text { direction }\end{array}$ \\
\hline Date And Time Of Fire & 1 & It is devoted to the date and time value of ignition/end time of fire \\
\hline $\begin{array}{l}\text { Info About The Fighting } \\
\text { Tool }\end{array}$ & UNLIMITED & $\begin{array}{l}\text { It defines the dimension of all information in case of Availability } \\
\text { Of Fighting Tool }\end{array}$ \\
\hline $\begin{array}{l}\text { Info About Fire Passes } \\
\text { Known Points }\end{array}$ & UNLIMITED & $\begin{array}{l}\text { It defines the dimension of all information if the wild fire passes } \\
\text { known points as a highway, .. etc. }\end{array}$ \\
\hline $\begin{array}{l}\text { Number Of Points In A } \\
\text { Contour }\end{array}$ & UNLIMITED & It is a index dimension to present the number of points in a contour \\
\hline $\begin{array}{l}\text { Number Of Observations } \\
\text { Of Contours }\end{array}$ & UNLIMITED & $\begin{array}{l}\text { It shows the number of observations for the fire contours. Each TObs } \\
\text {-for time of observation-is corresponding for a contour. Example: } \\
\text { at Tobs } 1=12 \mathrm{~h} 00 \text {, there is contour } 1 \text { and at Tobs } 2=12 \mathrm{~h} 25 \text {, there } \\
\text { is contour } 2 \text { in this case this dimension is } 2 \text {, it means that there are } \\
2 \text { contours with } 2 \text { times of observation }\end{array}$ \\
\hline Burned Surface & 1 & It is a index dimension to present the total burned surface \\
\hline Fire Spread Value & 1 & It defines the dimension of the value of the rate of spread \\
\hline $\begin{array}{l}\text { Number Of Observations } \\
\text { Of The Rate Of Fire } \\
\text { Spread }\end{array}$ & UNLIMITED & $\begin{array}{l}\text { It is a index dimension to present number of observations for the } \\
\text { rate of a fire spread }\end{array}$ \\
\hline Fire Intensity Value & 1 & It defines the dimension of the value of the fire intensity \\
\hline $\begin{array}{l}\text { Number Of Observations } \\
\text { Of The Fire Intensity }\end{array}$ & UNLIMITED & $\begin{array}{l}\text { It is a index dimension to present number of observations of the } \\
\text { fire intensity }\end{array}$ \\
\hline Smoke Height Value & 1 & It defines the dimension of the value of the fire smoke height \\
\hline $\begin{array}{l}\text { Number Of Observations } \\
\text { Of The Smoke Height }\end{array}$ & UNLIMITED & $\begin{array}{l}\text { It is a index dimension to present number of observations for the } \\
\text { height of smoke in the air }\end{array}$ \\
\hline Flame Height Value & 1 & It defines the dimension of the value of the fire flame height \\
\hline
\end{tabular}


Nader, Filippi, and Bisgambiglia

\begin{tabular}{|l|l|l|}
\hline $\begin{array}{l}\text { Number Of Observations } \\
\text { Of The Flame Height }\end{array}$ & UNLIMITED & $\begin{array}{l}\text { It is a index dimension to present number of observations for the } \\
\text { height of flame of such a fire }\end{array}$ \\
\hline
\end{tabular}

Table 3: Defined Variables for the proposed NetCDF framework.

\begin{tabular}{|l|l|l|l|}
\hline \multicolumn{1}{|c|}{ Variable } & \multicolumn{1}{c|}{ Type } & \multicolumn{1}{c|}{ Dimension } & Unit \\
\hline Fire ID & Custom & Fire Representation Text & - \\
\hline Fire Name & Custom & Fire Representation Text & - \\
\hline Fire Description & Custom & Fire Representation Text & - \\
\hline The Arrival Time Of Fire Line & Double & X, Y & $\mathrm{m} / \mathrm{s}$ \\
\hline Wind Speed & Double & Wind & degree \\
\hline Wind Direction & Double & Wind & - \\
\hline The Ignition Time Of Fire & Double & Date And Time For A Fire & - \\
\hline The Final Time Of Fire & Double & Date And Time For A Fire & - \\
\hline Ignition Points Of Fire & {$[$ Double, Double] } & Number Of Ignition Points, Point 2D & Ha \\
\hline Total Burned Surface & Double & Burned surface & - \\
\hline Availability Of Fighting Tool & Custom & Info About The Fighting Tool & - \\
\hline Fire Passes Known Points & Custom & Info About Fire Passes Known Points & - \\
\hline Front Contours & Custom & Number Of Observations Of Contours & - \\
\hline A Front Contour & {$[$ Double, Double] } & Number Of Points In A Contour, Point 2D & - \\
\hline Table Of Fire Spread & Custom & $\begin{array}{l}\text { Number Of Observations Of The Rate Of Fire } \\
\text { Spread }\end{array}$ & - \\
\hline Rate Of Fire Spread & Double & Fire spread Value & $m / s$ \\
\hline Table Of Fire Intensity & Custom & Number Of Observations Of The Fire Intensity & - \\
\hline Fire Intensity & Double & Fire intensity Value & $k W / m$ \\
\hline Table Of Smoke Height & Custom & Number Of Observations Of The Smoke Height & - \\
\hline Smoke Height & Double & Smoke Height Value & $m$ \\
\hline Table Of Flame Height & Custom & Number Of Observations Of The Flame Height & - \\
\hline Flame Height & Double & Flame Height Value & $m$ \\
\hline
\end{tabular}

Custom means a Compound Data type. Known data types are Float, Double, String, ..etc. Compound Data Type defines a collection of data types; by example Availability of fighting tool is a variable with a Compound Data type which consists of: Time of Alert [data type : String (text)], Time of Arrival [data type : String (text)], Description of Equipments [data type : String (text)], Description of Forces [data type : String (text)], Fire shape fought [data type : String (text)], Time of End Fighting [data type : String (text)] and Quantities of Water used [data type : String (text)].

\section{REFERENCES}

ARNOULD, P., and C. CALUGARU. 2008. "Incendies de forêts en Méditerranée : le trop dit, le mal dit, le non dit = Wildfire around the Mediterranean : too much said, or too badly, and too much left unsaid". Forêt méditerranéenne 29 (3): 281-296.

Balbi, J. H., F. Morandini, X. Silvani, J. B. Filippi, and F. Rinieri. 2009. "A physical model for wildland fires". Combustion and Flame 156 (12): 2217-2230.

Dumond, Y., S. Garitat, F. Gosse, E. Michelis, P. Simonpieri, and P. Tran. 2009. "Asphodèle-business-process oriented software for fighting forest fires.". Revue Forestière Française 61 (1): 9-19.

Eaton, B., J. Gregory, B. Drach, K. Taylor, and S. Hankin. 2006. "NetCDF Climate and Forecast (CF) Metadata Conventions". 


\section{Nader, Filippi, and Bisgambiglia}

Filippi, J. B., and J. H. Balbi. 2009. "Validation of a physics-based fire spread model and simulation method on a large wildfire accident". Int. J. of Wildland Fire, to appear.

Filippi, J. B., F. Morandini, J. H. Balbi, and D. R. Hill. 2010. "Discrete Event Front-tracking Simulation of a Physical Fire-spread Model". Simulation 86 (10): 629.

Finney, M. A. 1994a. "FARSITE: a fire area simulator for fire managers". In the Proceedings of The Biswell Symposium, Walnut Creek, California.

Finney, M. A. 1994b. "Modeling the spread and behavior of prescribed natural fires". In Proceedings of the 12th Conference on Fire and Forest Meteorology, edited by S. of American Foresters, 138-143.

Finney, M. A. 2006. "An overview of FlamMap fire modeling capabilities". In Fuels Management-How to Measure Success: Conference Proceedings, 213-220.

Finney, M. A., and K. C. Ryan. 1995. "Use of the FARSITE fire growth model for fire prediction in US National Parks". In The International Emergency Mgt. and Engineering Conf.: globalization of emergency management and engineering, national and international issues concerning research and applications, 183-189.

Flannigan, M. D., B. D. Amiro, K. A. Logan, B. J. Stocks, and B. M. Wotton. 2006. "Forest fires and climate change in the 21 st century". Mitigation and Adaptation Strategies for Global Change 11 (4): 847-859.

Keane, R. E., J. L. Garner, K. M. Schmidt, D. G. Long, J. P. Menakis, and M. A. Finney. 1998. "Development of input data layers for the FARSITE fire growth model for the Selway-Bitterroot Wilderness Complex, USA". Notes of U.S. Department of Agriculture, Forest Service, Rocky Mountain Research Station:66 p.

Miller, C., P. B. Landres, and P. B. Alaback. 2000. "Evaluating risks and benefits of wildland fire at landscape scales". Proceedings-Crossing the millennium: Integrating spatial technologies and ecological principles for a new age in fire management comp. LF Neuenschwander and KC Ryan, eds:78-87.

Ottmar, R. D., D. V. Sandberg, C. L. Riccardi, and S. J. Prichard. 2007. "An overview of the Fuel Characteristic Classification System-Quantifying, classifying, and creating fuelbeds for resource planning". Canadian Journal of Forest Research 37 (12): 2383-2393.

Rew, R. K., and G. P. Davis. 1990. "The unidata netCDF: Software for scientific data access". In Sixth International Conference on Interactive Information and Processing Systems for Meteorology, Oceanography, and Hydrology, Anaheim, California, American Meteorology Society, 33-40.

Rollins, M. G., R. E. Keane, Z. Zhu, J. Menakis, W. J. Hann, and A. J. Shlisky. 2003. "LANDFIRE: A nationally consistent and locally relevant interagency fire, fuels, and risk assessment". In Proceedings of 2nd International wildland fire ecology and fire management congress, 16-20.

Service, U. S. F. 1998. FARSITE: Fire Area Simulator-Model Development And Evaluation, Research Paper RMRS-RP-4, March 1998. s.n.

Zeigler, B. P. 1987. "Hierarchical, modular discrete-event modelling in an object-oriented environment". Simulation 49 (5): 219.

Zeigler, B. P., H. Praehofer, and T. G. Kim. 2000. Theory of modeling and simulation: integrating discrete event and continuous complex dynamic systems. Academic Press.

\section{AUTHOR BIOGRAPHIES}

BAHAA NADER is preparing a PhD, in the University of Corsica, France. His main research concern the incertitude of forest fires simulations in ForeFire. In 2009 he received the BSc in Computer and network engineering from the French University in Egypt, Egypt. In the same year he received a Master degree in computer science from University of Corsica, France.

JEAN BAPTISTE FILIPPIis a full time Researcher at the SPE CNRS laboratory of the university of Corsica. He has developed the ForeFire wildfire simulation software and is now leading a national project to provide coupled atmospheric/wildfire software.

PAUL ANTOINE BISGAMBIGLIAis professor of computer science at University of Corsica, Corsica (France) and head of the UMRS CNRS 6134. His research interests include multi-modeling activities and the use of various techniques combination in order to develop a framework for complex natural systems. He use a modeling and simulation formalism based on a discrete event specification (DEVS) proposed by B.P. Zeigler. 